\title{
Immunological and Functional Differences between Human Type I and II Colony-stimulating Factors
}

\author{
Ming-Chi Wu, Alan M. Miller, and Adel A. Yunis, Departments of Medicine, \\ Biochemistry and Oncology, University of Miami School of Medicine, and \\ Howard Hughes Medical Institute, Miami, Florida 33101
}

A B S T R A C T Two distinct types of colony-stimulating factor (CSF) have recently been described in human tissues and cultured cell lines. Antisera to purified type I and II CSF were prepared in rabbits. AntiCSF I antibody inhibits CSF I, but has no effect on CSF II. It cross-inhibits CSF I from several other human sources, but does not inhibit CSF from mouse lung or mouse L cells. Anti-CSF II antibody inhibits the activity of CSF II, but has no effect on CSF I. A radioimmunoassay for CSF I has been established. Competitive binding assay further demonstrated the immunological differences between CSF I and II. When CSF II is used to stimulate human marrow cells fractionated by sedimentation velocity, two populations of CFU-C are separated, one sedimenting at $8 \mathrm{~mm} / \mathrm{h}$ and forming colonies by day 7 , and a second sedimenting at $6.8 \mathrm{~mm} / \mathrm{h}$ and forming colonies by day 13. In contrast, CSF I does not stimulate colony growth by day 7 but does do so by day 13 in cells sedimenting between $7.2-8.5 \mathrm{~mm} / \mathrm{h}$. These results indicate that CSF I and II are distinct in their biochemical, immunological, and functional properties.

\section{INTRODUCTION}

We have recently reported that conditioned media prepared from a variety of human tissues and cultured cancer cells exhibit two distinct types of colonystimulating factor $(\mathrm{CSF})^{1}$ which can be separated by isoelectrofocusing and gel filtration chromatography. CSF I shows heterogeneity on IEF with $\mathrm{pI}$ in the range of 3.6-4.7 and has a molecular weight of 50,000. CSF

Dr. Wu is the recipient of Research Career Development Award CA 00868. Dr. Yunis is a Howard Hughes Investigator. Address reprint requests to Dr. Wu, Dept. of Medicine, University of Miami School of Medicine, Box 016960, Miami, Fla. 33101.

Received for publication 28 January 1981 and in revised form 2 March 1981.

${ }^{1}$ Abbreviations used in this paper: CFU-C; CSF, colonystimulating factor; IEF, isoelectrofocusing; MIA PaCa-2, cultured human pancreatic carcinoma.
II appears as a single peak with pI of 5.7 and has a molecular weight of 27,000 . CSF I stimulates mouse bone marrow CFU-C but has little or no activity in human marrow while CSF II is more active in human than in mouse marrow (1).

A number of important questions are raised by our observations particularly concerning the relationship between these two types of CSF and the significance of the so called "mouse" activity of type I CSF. If type I CSF plays any role in granulopoiesis in vivo, it must have biological activity on human marrow CFU-C. In our studies described here we demonstrate that $(a)$ in addition to differences in molecular weight, isoelectric point, and marrow specificity, type I and II CSF are immunologically distinct and $(b)$ the action of type I CSF appears to be directed to a specific subpopulation of human CFU-C.

\section{METHODS}

Fetal calf serum and horse serum were purchased from Flow Laboratories, Rockville, Md. Tissue culture medium (Dulbecco's modified Eagle's medium) was from Gibco Laboratories, Grand Island, N. Y. Carrier-free radioactive $\mathrm{Na}^{125}$ I was from New England Nuclear, Boston, Mass. All other chemicals were of reagent grade.

CSF assay. The standard method developed by Bradley and Metcalf was used with modification (2). The preparation of mouse and human bone marrow cells and the morphological identification of colonies have been described previously (1). A unit of CSF activity is arbitrarily defined as the amount of CSF which stimulates the formation of one colony under the specified assay conditions.

Production of antibodies against CSF I and II in rabbits. Purified CSF I $\left(0.1 \mathrm{mg}, 7 \times 10^{6} \mathrm{U}\right)$ and partially purified CSF II ( $\left.1.0 \mathrm{mg}, 1.2 \times 10^{6} \mathrm{U}\right)$ from cultured human pancreatic carcinoma (MIA PaCa-2) (3) were used to immunize rabbits according to procedures described previously (4). Preimmunized and immunized sera were treated with $33 \%$ saturated ammonium sulfate, and the globulin fraction was subjected to DEAE-cellulose chromatography according to the standard procedure. The purified IgG fractions (preimmunized and immunized) were reconstituted to the original serum volume in normal saline solution.

Cross-inhibition by antibodies. The antibodies thus prepared were used to study the cross-inhibition among dif- 

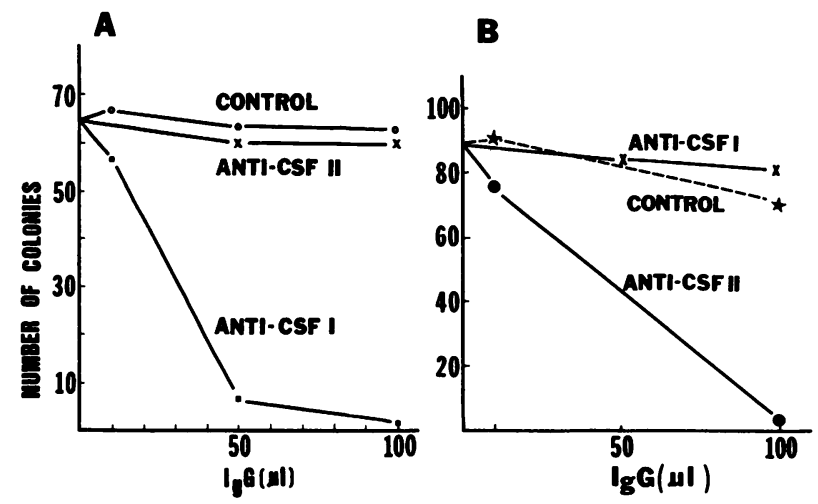

FIGURE 1 Effects of anti-CSF antibodies on CSF activity: CSF I (A) and CSF II (B) were each incubated with either anti-CSF I, anti-CSF II, or control IgG for $30 \mathrm{~min}$ at different concentrations and subsequently assayed for the ability to stimulate colony formation on mouse bone marrow (CSF I) or human bone marrow (CSF II). Results are expressed in colonies per $10^{5}$ cells.

ferent types of CSF. CSF I and CSF II from MIA PaCA-2 cells $(\sim 100 \mathrm{U})$ were incubated separately with $100 \mu \mathrm{l}$ of anti-CSF I antibody, anti-CSF II antibody, or control IgG for $30 \mathrm{~min}$ at room temperature and then assayed for activity. Similarly, CSF I from human placenta, lung, urine, leukocyte-conditioned media, and cultured squamous cell carcinoma, as well as mouse lung and $\mathrm{L}$ cell $\mathrm{CSF}$, were similarly incubated with anti-CSF I antibody to test for crossinhibition.

Iodination of CSF I. Purified type I CSF from MIA PaCa-2 cells $\left(5 \mu \mathrm{g}\right.$, specific activity, $7 \times 10^{7} \mathrm{U} / \mathrm{mg}$ ) was iodinated with carrier-free $\mathrm{Na}^{125} \mathrm{I}(2 \mathrm{mCi})$ according to the procedure of Greenwood et al. (5) as modified by Stanley (6). The iodinated ${ }^{125}$ I-CSF I was then purified on a Sephadex G-25 column (PD-10) followed by an Ultrogel AcA column (10 $\times 110 \mathrm{~mm}$, Column volume, $110 \mathrm{ml}$ ) equilibrated with phosphate-buffered saline. The ${ }^{125} \mathrm{I}-\mathrm{CSF}$ I thus prepared had a specific radioactivity of $10^{5} \mathrm{cpm} / \mathrm{ng}$ and at least $80 \%$ of the initial biological activity. Iodination efficiency was $\sim 10 \%$.

Radioimmunoassay (RIA) of CSF I. CSF samples from different sources were properly diluted with RIA buffer (50 mM phosphate buffer pH 6.5 containing $0.2 \%$ bovine serum albumin, $0.1 \% \mathrm{NaN}_{3}$, and $0.01 \%$ ethylene glycol 6000 ). $100 \mu \mathrm{l}$ of sample, $10 \mu \mathrm{l}$ of ${ }^{125}$ I-CSF I $(18,000 \mathrm{cpm})$ in RIA buffer, and $25 \mu \mathrm{l}$ of diluted anti-CSF I antibody were mixed in that order. RIA buffer was added to a final volume of 200 $\mu$ l. The radioactivity of all samples was counted and the samples were then incubated overnight at $4^{\circ} \mathrm{C}$. Undiluted control IgG $(100 \mu \mathrm{l})$ was added to each tube, followed by $200 \mu \mathrm{l}$ of saturated ammonium sulfate solution ( $\mathrm{pH}$ adjusted to 7.0). The precipitates were left in ice for $30 \mathrm{~min}$ and then centrifuged at $10,000 \mathrm{rpm}$ (Sorvall RC-5B, SS-34 Rotor). The supernates were removed and the radioactivity of the precipitates measured in a gamma counter (Nuclear Chicago Des Plaines, Ill.). The amount of anti-CSF I antibody used in the assay was equivalent to the concentration which produced a bound/free ratio $(B / F)$ of $\sim 1.0$. In our study, the $B / F$ ratio from one batch of ${ }^{125}$ I CSF I and anti-CSF I could be kept relatively constant for $\sim 1$ wk.

Competitive binding of CSF I and CSF II. CSF I from several sources including MIA PaCa-2 cells, human lung, and human placenta were partially purified by isoelectrofocusing and gel filtration chromatography as described previously (1). Samples containing CSF activities in the range of 0.1 to $1,000 \mathrm{U}$ in $100 \mu$ l of RIA buffer were used in the RIA competitive binding studies as described above. Partially purified CSF II from MIA $\mathrm{PaCa}-2$ cells was also used to compare the competitive binding of CSF I and II to the anti-CSF I antibody.

Fractionation of human bone marrow cells by sedimentation at unit gravity. The preparation of human bone marrow cells and fractionation by sedimentation velocity on the Sta-Put apparatus have been described previously (7). A total of 1.4-1.8 $\times 10^{8}$ cells were layered over a continuous bovine serum albumin gradient of 0.5 to $2.0 \%$ and allowed to sediment for $3.5 \mathrm{~h}$ at $4^{\circ} \mathrm{C}$. Cell fractions were collected from the bottom of the separation chamber and assayed for CFU-C with either CSF I or CSF II obtained from human lung conditioned medium (8) after isoelectrofocusing and gel filtration chromatography (1).

\section{RESULTS}

Inhibition of CSF I and II by antibodies. As shown in Fig. 1, when CSF I was incubated with control IgG, anti-CSF I IgG, and anti-CSF II IgG, the activity as assayed on mouse marrow cells was inhibited only by anti-CSF I; there was no inhibition by anti-CSF II or control IgG. Similarly, the activity of CSF II as assayed on human bone marrow cells was specifically inhibited by anti-CSF II antibody. The results clearly indicate that CSF I and II are immunologically distinct. Anti-CSF I also cross-inhibited CSF I from human lung, placenta, and urine, but showed no effect on CSF from mouse lung and mouse L cells (Table I).

Competitive binding of CSF I and II-RIA. Using anti-CSF I antibody and radioiodinated ${ }^{125}$ I-CSF I, an

TABLE I

The Effect of Anti-CSF I Antibody on CSF from Different Sources

\begin{tabular}{lccc}
\hline Source of CSF & $\begin{array}{c}\text { Control } \\
\text { colonies }\end{array}$ & $\begin{array}{c}\text { Colonies } \\
\text { AB-treated }\end{array}$ & $\begin{array}{c}\text { Control } \\
\text { colonies }\end{array}$ \\
\hline & & & $\%$ \\
MIA PaCa-2 & & & \\
CSF I & 97 & 0 & 0 \\
MIA PaCa-2 & & & \\
CSF II & 71 & 62 & 88 \\
HPCM & & & \\
CSF I & 95 & 0 & 0 \\
HLCM & & & \\
CSF I & 110 & 0 & 0 \\
Urinary CSF & 89 & 0 & 0 \\
Mouse lung & 75 & 74 & 98 \\
Mouse L cells & 56 & 53 & 96 \\
\hline
\end{tabular}

CSF from different sources was incubated with $100 \mu \mathrm{l}$ of anti-CSF I antibody or control IgG at room temperature for $30 \mathrm{~min}$ in the assay plates and then assayed on mouse marrow. HPCM, human placental conditioned medium; HLCM, human lung conditioned medium; AB, antibody. 
RIA has been established. A typical competitive binding curve with CSF I and II is shown in Fig. 2. CSF II from MIA $\mathrm{PaCa}-2$ showed no competition for binding while CSF I from MIA PaCa-2, human lung, and human placenta competed to the same degree. Once again, these results demonstrate the immunological difference between CSF I and II.

Stimulation of different bone marrow $C F U-C$ populations by CSF I and II. The sedimentation pattern of human bone marrow cells as assayed with CSF I and II from human lung is shown in Fig. 3. When CSF II was used to assay the various fractions, two broad CFU-C peaks were observed. One peak, with a sedimentation velocity of $8-8.5 \mathrm{~mm} / \mathrm{h}$, formed colonies by day 7 of culture and another peak sedimenting at $6.5 \mathrm{~mm} / \mathrm{h}$ formed colonies by day 13 . In contrast, CSF I stimulated little or no colony formation in any fractions on day 7. Instead, a new, broad CFU-C peak appeared between 7 and $9 \mathrm{~mm} / \mathrm{h}$ on day 13 of culture.

Colony morphology in fractionated marrow, in response to the two types of CSF, was also different. Colonies formed in response to type II CSF were predominantly granulocytic on day $7(84 \%)$, becoming predominantly macrophagic by day 13 . Colonies formed in response to type I CSF on day 13 were $70 \%$ granulocytic in the low-sedimenting $(6.8 \mathrm{~mm} / \mathrm{h})$ and $42 \%$ granulocytic in the high-sedimenting $(8.5$ $\mathrm{mm} / \mathrm{h}$ ) fractions. This was still more than double the percentage seen with type II CSF in the same fractions.

\section{DISCUSSION}

A common pattern of two distinct types of CSF in human tissue and cultured cancer cells has been recently reported. CSF I and II can be separated by

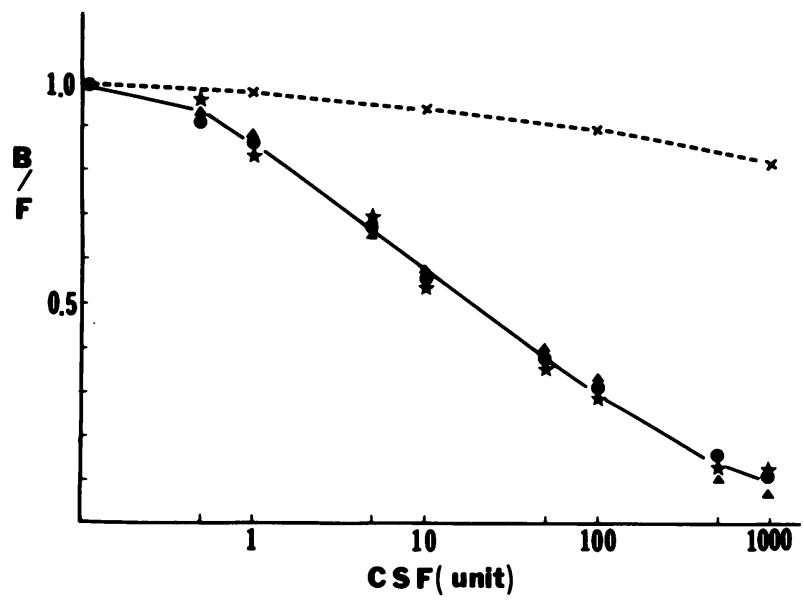

FIGURE 2 Competitive binding curve for CSF from different sources. Ordinate, the ratio of bound ${ }^{125} \mathrm{I}-\mathrm{CSF}$ to free ${ }^{125}$ I-CSF; abscissa, CSF activity in units per assay tube. MIA PaCa-2 CSF II $(\times)$; MIA PaCa-2 CSF I (๑); human lung CSF I (A); human placenta CSF I $(\star)$.

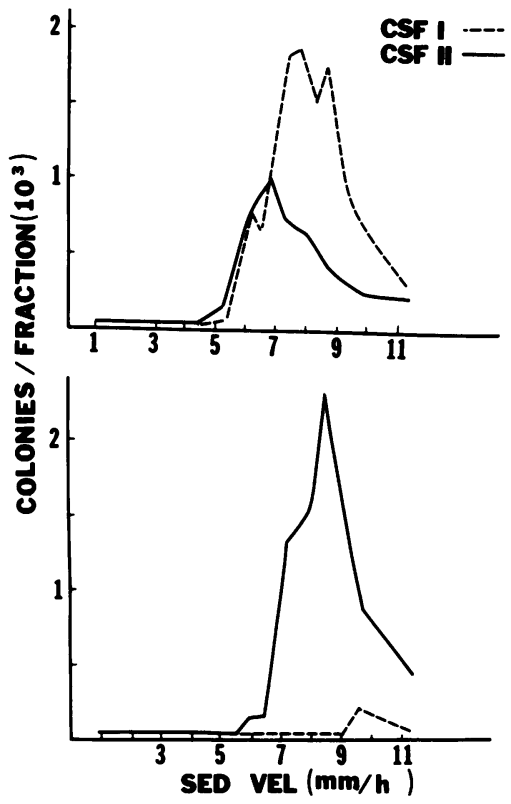

FIGURE 3 Heterogeneity of CFU-C in response to type I and II CSF. Human bone marrow cells were fractionated by sedimentation velocity at unit gravity. Fractions were assayed for colony formation with CSF I and II separately. Plates were read at days 7 (bottom) and 13 (top). The activity of the CSF I and II in unfractionated marrow was, respectively, as follows: day $7,4.5$ and 74.5 colonies $/ 10^{5}$ cells; day 13,30 and 13 colonies $/ 10^{5}$ cells.

isoelectrofocusing and gel filtration, and have different pI, molecular weights, and marrow specificity (1). The results presented in this report demonstrate that type I and II CSF are also immunologically distinct. Anti-CSF I antibody inhibits CSF I, but not CSF II activity, whereas anti-CSF II antibody inhibits CSF II but not CSF I. The immunological difference between type I and type II CSF was further demonstrated by the competitive binding experiment using radioiodinated type I CSF.

The non-equivalence of human and mouse marrow cultured in the assay of CSF has been reported previously (9). It is known that human urinary CSF is active in mouse marrow, but that it exhibits little or no activity in human marrow. Our results indicate that human urinary CSF can be totally inhibited by anti-CSF I antibody. Thus, human urinary CSF is biologically and immunologically similar to CSF I. These findings are in agreement with those of Das et al. (10) who recently demonstrated, using a radioreceptor assay method, that human urinary CSF is similar to the mouse active CSF obtained from different human sources.

Because of its low activity in human marrow, CSF I has been referred to as "mouse active," and its role as a stimulator of human CSF-C growth has been neglected. However, it is clear from the present studies 
that CSF $I$ is indeed active in human marrow, but that its activity is directed at a subpopulation of CFU-C which is best demonstrated on day 13 of culture and when this subpopulation is concentrated by fractionation.

When human marrow cells are fractionated by sedimentation velocity at unit gravity and cells in the various fractions are cultured in the presence of human lung-conditioned medium as a source of CSF (8), two CFU-C peaks are observed (7), one sedimenting at $\sim 8-8.5 \mathrm{~mm} / \mathrm{h}$ and forming colonies after $7 \mathrm{~d}$ of culture, and a second sedimenting at $6.5 \mathrm{~mm} / \mathrm{h}$ and not forming colonies until at least the 11th $\mathrm{d}$ of culture. A similar CFU-C profile was obtained here using human lung CSF II. In contrast, when lung CSF I was used, essentially one CFU-C peak was obtained, exhibiting colonies on day 13 but having an average sedimentation velocity different from that of the 13-d peak seen with CSF II. Additionally, whereas most of the 13-d colonies with CSF II were macrophagic, those with CSF I were $42-80 \%$ granulocytic. The virtual absence of 7-d colonies with CSF I offers a good explanation as to why "human activity" of CSF I has not been evident in the routine 7-d assay in the past.

It is clear from our studies that CSF I and II are biochemically and immunologically distinct and appear to have a different CFU-C specificity. Perhaps more important is that the so called "mouse active" CSF I is also "human active" and should be looked at in a different perspective.

\section{ACKNOWLEDGMENTS}

The authors express their sincere thanks to John K. Cini and Mary Ann Gross for their excellent technical assistance.
This work was supported in part by U. S. Public Health Service grants AM-26207, CA-19182, and CA-14395.

\section{REFERENCES}

1. Wu, M-C., and A. A. Yunis. 1980. Common pattern of two distinct types of colony-stimulating factor in human tissues and cultured cells. J. Clin. Invest. 65: 772-775.

2. Ratzan, R. J., M. A. S. Moore, and A. A. Yunis. 1974. Effect of chloramphenicol and thiamphenicol on the in vitro colony forming cell. Blood. 43: 363-369.

3. Wu, M-C., J. K. Cini, and A. A. Yunis. 1979. Purification of a colony-stimulating factor from cultured pancreatic carcinoma cells. J. Biol. Chem. 254: 6226-6228.

4. Fojo, S. S., M-C. Wu, M. A. Gross, Y. Purcell, and A. A. Yunis. 1978. Purification and characterization of a colonystimulating factor from human lung. Biochemistry. 17: 3109-3116.

5. Greenwood, F. C., W. M. Hunter, and J. A. Glover. 1963. The preparation of ${ }^{131}$ I-labelled human growth hormone of high specific radioactivity. Biochem. J. 89: 114-123.

6. Stanley, E. R. 1979. Colony stimulating factor (CSF) radioimmunoassay: Detection of a CSF subclass stimulating macrophage production. Proc. Natl. Acad.Sci.U.S.A. 76: 2969-2973.

7. Miller, A. M., M. A. Gross, and A. A. Yunis. 1978. Heterogeneity of human colony forming cells (CFU-C): difference in size, rate of colony formation, and responsiveness to colony stimulating factor. J. Lab. Clin. Med. 92: 38-42.

8. Fojo, S. S., M-C. Wu, M. A. Gross, and A. A. Yunis. 1977. The isolation and characterization of a colony stimulating factor from human lung. Biochim. Biophys. Acta. 494: 92-99.

9. Lind, D. E., M. L. Bradley, F. W. Gunz, and P. C. Vincent. 1974. The nonequivalence of mouse and human marrow culture in the assay of granulopoietic stimulatory factors. J. Cell. Physiol. 83: 35-42.

10. Das, S. K., E. R. Stanley, L. J. Guilbert, and L. W. Forman. 1980. Discrimination of a colony stimulating factor subclass by a specific receptor on a macrophage cell line. J. Cell. Physiol. 104: 359-366. 